\title{
A study of radicals in industrial raw cristobalite powders
}

FRANCESCO DI BENEDETTO $^{1}$, ANDREA GIACCHERINI ${ }^{2}$, MAURIZIO ROMANELLI ${ }^{1}$, GIORDANO MONTEGROSSI ${ }^{3}$, Elena Belluso ${ }^{4}$, Silvana CAPELla ${ }^{4}$, Alfonso

ZOLEO $^{6}$, GIULIO ARCANGELI ${ }^{7}$, AlESSANDRO MARINACCIO $^{8}$, OTTORINO GOTTARDO ${ }^{9}$ AND FABIO $\mathrm{CAPACCI}^{10}$

${ }^{1}$ Dipartimento di Scienze della Terra, Università degli Studi di Firenze, Firenze, Italy.

${ }^{2}$ Dipartimento di Ingegneria Industria-le, Università degli Studi di Firenze, Firenze, Italy

${ }^{3}$ Istituto di Geoscienze e Georisorse (CNR-IGG), Firenze, Italy

${ }^{4}$ Dipartimento di Scienze della Terra \& "G. Scansetti" Centro Interdipartimentale per lo studio degli Asbesti e di altri Particolati Nocivi, Università degli Studi di Torino, Torino, Italy

${ }^{5}$ Dipartimento di Scienze Chimiche, Università di Padova, Padova, Italy

${ }^{6}$ Dipartimento di Medicina Sperimentale e Clinica, Università degli Studi di Firenze, Firenze, Italy

${ }^{7}$ INAIL, Laboratorio di Epidemiologia Occupazionale ed Ambientale, Roma, Italy

${ }^{8}$ Azienda ULSS 6 Euganea, Padova, Italy

${ }^{9}$ Health Agency of Florence, Firenze, Italy

In this study, we report the results of an experimental multianalytical characterisation of industrial cristobalite powders, used as raw materials for the artificial stone production. Cristobalite is considered a serious threat to the human health, being clas-sified as a group 1 carcinogen by the IARC. The study was carried out through X-ray Diffraction (XRD), Scanning Electron Microscopy with Energy Dispersive microanalysis (SEM/EDS), continuous wave (cw) and pulse Electron Paramagnetic Res-onance (EPR) spectroscopy. Our results, while confirming the almost exclusive presence of cristobalite in the powders, point out a sub-micrometric size of the structural coherence, associated to numerous stacking defects. Moreover, the material was found characterised by a relevant population of superoxide radicals, whose persistence appears conceivably long. Their presence in a material synthesized through a high temperature treatment points to a critical role of the grinding step in the industrial production of cristobalite. During this process, in fact, both superoxide generation and the presence of a substantial structural defectivity are induced. Indeed, cristobalite powders already result activated by a radical population, before any kind of process in the artificial stone production. 